\title{
Water Allocation Strategies for the Kat Basin in South Africa: Comparing Negotiation Tools and Game Theory Models
}

\author{
Ariel Dinar, World Bank, USA \\ Stefano Farolfi, CIRAD and University of Pretoria, South Africa \\ Fioravante Patrone, University of Genoa, Italy \\ Kate Rowntree, Rhodes University, South Africa
}

\begin{abstract}
Governments and developing agencies promote participatory approaches in solving common pool resource problems such as in the water sector. Two main participatory approaches have been applied separately, namely negotiation and mediation. In this paper we apply the RolePlaying Game that is a component of the Companion Modeling approach-a negotiation procedure, and Cooperative Game Theory (Shapley value and the Nucleolus solution concepts) that can be mirrored as a mediated mechanism, to a water allocation problem in the Kat watershed in South Africa. While the absolute results of the two approaches differ, the negotiation and the cooperative game theory provide similar shares of the benefit allocated to the players from various cooperative arrangements. By evaluating the two approaches, the paper provides useful tips for future extension for both the Role-Playing Game and the Cooperative Game Theory applications.
\end{abstract}

World Bank Policy Research Working Paper 4083, December 2006

The Policy Research Working Paper Series disseminates the findings of work in progress to encourage the exchange of ideas about development issues. An objective of the series is to get the findings out quickly, even if the presentations are less than fully polished. The papers carry the names of the authors and should be cited accordingly. The findings, interpretations, and conclusions expressed in this paper are entirely those of the authors. They do not necessarily represent the view of the World Bank, its Executive Directors, or the countries they represent. Policy Research Working Papers are available online at http://econ.worldbank.org. 


\section{Introduction}

Common Pool Resources (CPR) are those resources to which a community rather than a private individual has right of access, and which are managed jointly by that community. Examples of such resources, the arising conflicts, and the management arrangements among the community members, who may have free access, include grazing land (Goodhue and McCarthy, 2006), watershed resources (Anderson and Ford, 1994), fisheries (Munro, 1979), and irrigation water (Ostrom, 2002; Aadland and Kolpin, 2004).

Common pool resource disputes are increasing, due to increase in competition and deterioration of quality. Cooperative/participatory arrangements have long been in the center of public interest, especially regarding the mechanisms used by communities to share and manage the resource. Governments and development agencies promote participatory approaches that allow the stakeholders to agree on the arrangements by which the common property resource is managed, allocated and used. Negotiation approaches (NAs) have been used by communities as a cooperative mechanism to solving CPR problems (Steins and Edwards, 1999; Ostrom et al., 1999). In parallel, Cooperative Game Theory (CGT) that can be seen as an agreed upon mediated mechanism, which, among other things, explores the conditions supporting specific mediated solutions, has been applied with success to many CPR problems (see review of relevant literature by Parachino et al., 2006).

Although the two approaches of negotiation and cooperative game theory come from different directions and are both based on different assumptions, they complement each other in that they are both based on the principles of fairness that were suggested by Carraro et al (2005b:39) "The perception of fairness plays a crucial role in determining how a surplus is divided, and the potential allocation rules must be perceived as 'equitable' and 'envy-free' by all parties". These principles of fairness together with the efficiency principle lead, under certain circumstances, to stable cooperative outcomes.

NAs focus on the resolution of conflicts originating from stakeholders' different perceptions and use of natural resources. Recent literature on environmental management and catchment management in particular, places strong emphasis on achieving negotiated settlements to such conflicts (Becu et al., 2003). In the water sector, there have been many applications of both NA and CGT at various levels, starting from sectoral through international (Carraro et al., 
2005a; Parrachino et al., 2006). So far, the literature has applied separately NA and CGT to evaluate allocation issues and has not attempted comparing the NA and the CGT solutions. Other authors argue that participation in knowledge-sharing for water is a fundamental requirement for efficient and equitable use because of the cumulative effects of individual actions on the patterns of water use at the irrigation system and river basin scale (Lankford and Watson, 2006). Although it is expected that, under certain conditions of interaction among the parties, NA and the CGT will lead to similar allocation solutions, there is still no clear empirical evidence that this is the case.

In this paper we apply a negotiation procedure and a CGT solution approach to a water allocation problem in the Kat watershed in South Africa. We use simplifying assumptions to allow an evaluation, based on similar parameters, of the allocation solutions. We apply a RolePlaying Game (RPG) that is a component of the Companion Modeling approach (Barreteau et al. 2004), which has already demonstrated its usefulness in promoting discussion among stakeholders with contrasted and eventually conflicting viewpoints (Dray et al. 2006). We then formulate the same allocation problem also as a CGT problem, explaining and evaluating a couple of allocation solutions concepts (Shapley value and the Nucleolus): these allocations in our case are contained in the core, which means that they enjoy a relevant stability property. We explain sources for differences between the RPG and the CGT. Although the approach is centered on a specific case, the general issue of stable allocation arrangements in a watershed that is characterized by multiple externalities is of interest to many around the world. Therefore, this paper is aimed to demonstrate the application and usefulness of the Cooperative Game Theory and the Role Playing Game methods.

The next section provides a short description of the geographical, historical, political and institutional aspects in the Kat watershed. Then, the water allocation issues in that watershed are then discussed. The fourth section formulates the water allocation problem as a negotiation game and the fifth section presents the cooperative game solution to the allocation problem. Section 6 evaluates and explains differences, and section 7 provides possible extensions. The paper is then concluded. 


\section{The Kat watershed in South Africa ${ }^{1}$}

The Kat River valley (Figure 1), a tributary of the Great Fish River, is situated in the Eastern Cape province of South Africa. Although the watershed has a relatively high rainfall, much of the climate of the $1,700 \mathrm{~km}^{2}$ catchment is sub-humid to semi-arid. The fertile valley land can be utilized only through irrigation, using water from the Kat River. Prior to 1969, irrigators relied on the natural flow in the river, but since 1969 water from the Kat Dam (a 24 million cubic meters $\left(\mathrm{Mm}^{3}\right)$ storage capacity) has been available. While irrigation takes up the majority of the water in the catchment, domestic water users (about 49,500 inhabitants in 2001) represent an important component in the demand for water in the catchment.

Figure 1: Map of the Kat Catchment and the stylized sub-catchments in the RPG (for the conversion factors used see Table 1)
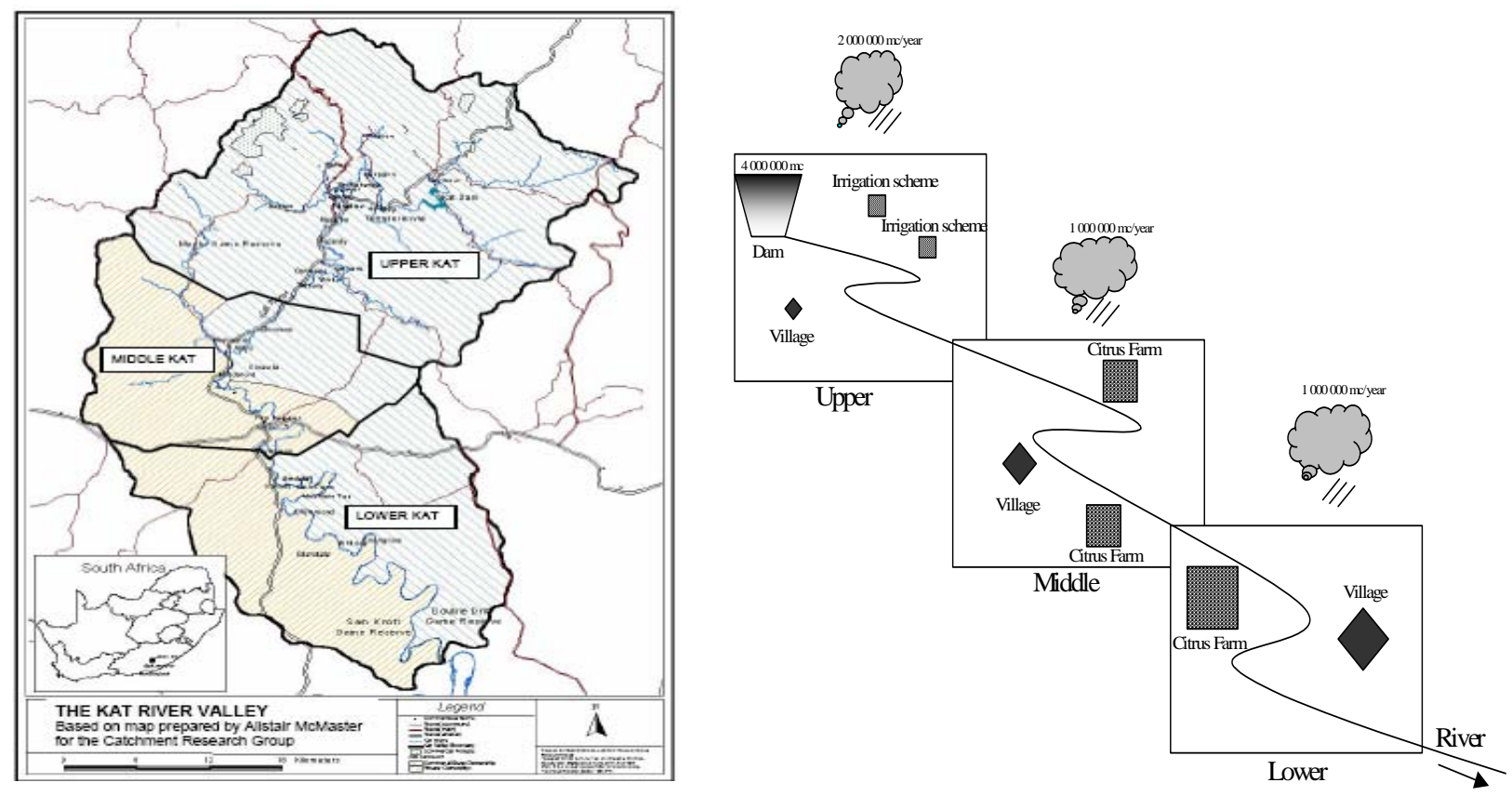

Source: Left panel is based on map prepared by Alistair McMaster. (McMaster 2002).

Four groups of irrigators can be identified in the Kat Valley: small-scale black farmers, often forming cooperatives; large-scale 'emerging' black farmers²; white commercial farmers with scheduled water rights; and white commercial farmers without scheduled water rights. The 
main water related stakeholders in the Kat Valley are therefore (1) the four groups of irrigators, (2) domestic water users and (3) the Municipality of Nkonkombe. The South African Department of Water Affairs and Forestry (DWAF), currently operating the Kat Dam, is considered the fourth important stakeholder in the system. The complex and contentious political history of the valley has given rise to a power dynamics that historically has favored the white commercial farmers producing citrus who controlled water use through the Kat River Irrigation Board (IB). ${ }^{3}$

\section{Water allocation issues in the Kat watershed}

Water sources in the Kat River valley are currently almost exclusively from surface water. Some groundwater developments are foreseen in the near future and this could increase water availability in the catchment by nearly 10 percent (DWAF, 2001). ${ }^{4}$ As mentioned above, decisions about water allocation strategies will become the responsibility of the recently established Water User Association (WUA), which represents the various groups of stakeholders in the catchment.

Irrigated agriculture at present is the largest water user in the catchment, accounting for $60 \%$ of the total water requirements, including the environmental flow requirement, the ecological Reserve ${ }^{5}(12 \%)$. Domestic uses (13\%), afforestation (10\%) and losses due to alien vegetation (5\%) are the other requirements in the catchment. The recent history of South Africa led to the co-existence of different groups of irrigators in the catchment. These farmers are located in specific portions of the catchment ${ }^{6}$ (Figure 1), namely smallholders and emerging farmers in the Upper sub-catchment (U), emerging and large-scale farmers in the Middle subcatchment (M) and large-scale farmers in the Lower sub-catchment (L) (Farolfi and Rowntree, 2005).

Domestic water consumption per capita is low by modern standards, mainly due to striking rural poverty and limited services (Farolfi and Abrams, 2005). A crucial issue for the National Water Resource Strategy of South Africa is the protection of environmental and ecological needs, which is translated into the definition and respect of the ecological reserve in each catchment. Therefore, we take it as granted that the WUA that represents the water users respects the ecological reserve. 
The Kat River Dam is certainly the main tool for water supply management in the catchment. The dam is currently operated by DWAF based on a mechanism of water licenses and scheduled and non-scheduled users. It is expected that soon the WUA will be responsible for the management of the dam. Therefore, in this paper we assume that it is the WUA and not DWAF that decides on dam water allocation. Future demands were identified (Farolfi-Abrams, 2005) to include increase in citrus area; increase in small-scale irrigation schemes; increase in domestic uses, particularly in rural areas; more tourism, game farms and, possibly, golf courses. These will be addressed in future analyses.

\section{Formulating water allocation decisions as a negotiation process}

To facilitate discussions about water allocation strategies within the Kat River WUA, stakeholders' representatives accepted to take part in a process of Companion Modeling (Barreteau et al., 2003) consisting of an iterative and participatory development of a simulation model-KatAware (Farolfi and Bonté, 2005) that illustrates alternative scenarios of water allocation in the catchment (Farolfi and Rowntree, 2005).

An important component of Companion Modeling is the use of Role-Playing Games (RPG) to facilitate stakeholders' comprehension of the developing model and to allow modelers better understanding of stakeholders' strategies and behavior. For this purpose, a RPG was constructed based on the model KatAware, which is being developed with the WUA following the Companion Modeling approach.

In the RPG, the Kat catchment (Figure 1) is divided into three sub-catchments corresponding to the three mentioned areas: Upper, Middle and Lower. For the purpose of this game, two smallholding irrigation schemes (20 ha each) ${ }^{7}$ are located in the Upper Sub-catchment (U), two citrus farmers (30 ha each) are located in the Middle Sub-catchment (M) and a citrus farmer (40 ha) is in the Lower Sub-catchment (L). Farmers have irrigated land on which they produce cabbages if they are smallholders or citrus if they are large-scale farmers. Domestic water users live in three villages: one in U (3 000 inhab), one in M (5 000 inhab) and one in L (15 000 inhab). An average amount of rainfall equivalent to 2 million $\mathrm{m}^{3} /$ year falls on $\mathrm{U}$, whilst annual rainfall equivalent to 1 million $\mathrm{m}^{3} /$ year falls on the $\mathrm{M}$ and on $\mathrm{L}$. A dam with a storage capacity of 4 million $\mathrm{m}^{3}$ is located in U. A Water Users Association (WUA) exists in the catchment and is responsible for water management and allocation according to the principles of 
Social Equity, Environmental Sustainability and Economic Efficiency as indicated in the Water Legislation of South Africa. All players are members of the WUA.

To simplify the game while reflecting its reality, data representing the actual catchment are transformed into values that are proportional to the real ones, and only 8 players are left to interact (table 1$)^{8}$. The primary goal of the game is to allow for the available water resource of the catchment as a whole to be managed in a sustainable way, taking into consideration the above-mentioned principles. At the same time, the goal for each player is to maximize his or her individual economic gain and if they are a village manager to maximize also villagers' satisfaction (see additional discussion in the CGT section), within the context of the group goal. The game is set to allow sessions of seven simulated years. This choice is a compromise between playability and a time span sufficient to provide elements of discussion on mid-term consequences of water allocation. The RPG session presented here spans over six years.

Table 1: Actual and transformed values for use in the RPG of main variables in the Kat Basin

\begin{tabular}{lrc}
\hline Variable & Actual values & Values in the RPG \\
\hline Dam Capacity $\left(\mathrm{Mm}^{3}\right)$ & $24,000,000$ & $4,000,000$ \\
\hline Natural runoff $\left(\mathrm{Mm}^{3}\right)$ & $13,500,000$ & $3,300,000$ \\
\hline Domestic consumption $\left(\mathrm{Mm}^{3}\right)$ & $1,500,000$ & 580,000 \\
\hline Irrigation consumption $\left(\mathrm{Mm}^{3}\right)$ & $11,000,000$ & $1,064,000$ \\
\hline Cabbage area (ha) & 180 & 40 \\
\hline Citrus area (ha) & 1,300 & 23,000 \\
\hline Inhabitants in catchment & 49,000 & 550,000 \\
\hline Annual outflow & $1,600,000$ & 100 \\
\hline
\end{tabular}

At the beginning of the game farmers receive the number of hectares corresponding to their farm (or irrigation scheme) and for each hectare a symbol corresponding to their production (cabbage or citrus). As the game progresses, farmers also receive an amount of money corresponding to their previous year's profit and a number of workers indicating how many permanent or seasonal employees they hired the previous season ${ }^{9}$. Every year farmers may decide to increase or reduce their irrigated area. They can also decide to change their crop 
(cabbage to citrus or vice versa). If they decide to plant new citrus, they can choose a more advanced irrigation technology (drip), which would cost more but will save water. Cabbage producers can decide to have 1 cycle, 2 cycles or 3 cycles of cabbage production per year on their fields. Budgets and water consumption data for citrus and cabbage are provided to farmers at the beginning of the game. Village managers receive, and pay for, bulk water from the WUA that manages the entire water in the catchment and provide water services (including water distribution) to the households of each village. They start with a given ratio of water sources for the households of their village. These water sources are: river water; collective tap; indwelling tap. Each water source has a different cost (investment + operating cost) that has to be added to the cost of the bulk water the managers "buy" from the WUA. Village managers can charge their inhabitants with a per capita tariff for the water services they provide, and this corresponds to their annual income. The households derive a certain level of satisfaction (utility) from their income that can be spent on consumption goods. Because households have different levels of effort associated with the various water sources they are provided with, they also obtain different levels of utility from each of the three sources of water.

The village manager's objective is twofold. First to maximize his or her profit resulting from the difference between the tariff collection and the water provision cost + bulk water cost and at the same time maximize the sum of households' utility. Elements of budgets and utility values for households are provided to local village managers at the beginning of the game.

A number of factors varying annually, such as rainfall, market prices and population dynamics can influence players’ strategies.

\subsection{Negotiation results}

This section illustrates some outcomes of a RPG session held in the Kat catchment in November 2005. The set-up of the game and the players participating in the session are presented in the right-hand side rectangle of Figure 1. The initial values characterizing each player are presented in the left column of Table 2, which also includes final values (end of year 6 of the negotiation game). In the tables that follow, year 1 is the initial state and was set by the game facilitators; years 2 to 6 were actually played.

Table 2 shows the initial and final values of the exogenous factors controlled by the game operators. The game facilitators introduced a general trend of increasing water scarcity. This 
stress was produced by a combination of lower rainfall and increasing population in the catchment. Some marginal changes (mainly reductions) affected crop prices. A relatively low level of uncertainty was introduced in the session, corresponding to a small difference between expected (forecasted) and actual exogenous factors to which stakeholders were confronted.

Table 2 - Exogenous factors in the RPG session: initial, final and Difference values.

\begin{tabular}{lrrr}
\hline Variable & Initial & \multicolumn{1}{c}{ Final } & Difference \% \\
\hline Rainfall Upper $\left(\mathrm{m}^{3}\right)$ & $2.000,000$ & $1.400,000$ & -30 \\
\hline Rainfall Middle $\left(\mathrm{m}^{3}\right)$ & $1,000,000$ & 600,000 & -40 \\
\hline Rainfall Lower $\left(\mathrm{m}^{3}\right)$ & $1,000,000$ & 600,000 & -40 \\
\hline Population Upper (inhab.) & 3,000 & 3,500 & 17 \\
\hline Population Middle (inhab.) & 5,000 & 5,500 & 10 \\
\hline Population Lower (inhab.) & 15,000 & 16,000 & 7 \\
\hline Market Price Citrus (R/ton) & 2,000 & 2,000 & -17 \\
\hline Market Price Cabbage & 6.00 & 5.00 & 0 \\
\hline
\end{tabular}

Note: $\mathrm{R}=$ Rand, the South African currency. $1 \mathrm{USD}=6$ Rand at the time of the experiment.

Clear differences in behavior and strategies among players were observed for the different sectors and in the three sub-catchments (Table 3 and 4). In the $U$ the two irrigation schemes opted first for an intensification of their cabbage productions (from 2 to 3 cycles per year). Only at the end of the RPG session the second irrigation scheme decided to reduce the cultivated area by $50 \%$. In the $\mathrm{M}$, the two citrus farmers adopted two very different strategies, one farmer opted first towards diversification (cabbage in addition to citrus) and then abandoned citrus, whilst the other farmer kept the citrus area constant but also planted an equivalent area of cabbage. In L, the large citrus farm adopted a quite "conservative" strategy consisting of reducing the planted area of citrus by $25 \%$ and not moving to cabbage. All new citrus plantations in the three farms were equipped with advanced irrigation technologies, consisting of drip systems, more costly in terms of investment, but water saving. 
Table 3: Strategies and outcomes for the 5 farms during the RPG session: initial and final values

\begin{tabular}{|c|c|c|c|}
\hline & Initial & Final & Difference (\%) \\
\hline \multicolumn{4}{|c|}{ Irrigation Scheme 1(U) } \\
\hline Ha citrus old technology & 0 & 0 & 0.0 \\
\hline Ha citrus new technology & 0 & 0 & 0.0 \\
\hline Ha cabbage & 20 & 20 & 0.0 \\
\hline Cycles cabbage & 2 & 3 & 50.0 \\
\hline Total Ha & 20 & 20 & 0.0 \\
\hline Employment (n) & 51 & 76.6 & 50.1 \\
\hline Profit (R) & 64,208 & 250,000 & 289.4 \\
\hline \multicolumn{4}{|c|}{ Irrigation Scheme $2(\mathrm{U})$} \\
\hline Ha citrus old technology & 0 & 0 & 0.0 \\
\hline Ha citrus new technology & 0 & 0 & 0.0 \\
\hline Ha cabbage & 20 & 10 & -50.0 \\
\hline Cycles cabbage & 2 & 2 & 0.0 \\
\hline Total Ha & 20 & 10 & -50.0 \\
\hline Employment (n) & 51 & 25 & -51.0 \\
\hline Profit (R) & 64,208 & 250,000 & 289.4 \\
\hline \multicolumn{4}{|c|}{ Citrus Farm 1 (M) } \\
\hline Ha citrus old technology & 30 & 0 & -100.0 \\
\hline Ha citrus new technology & 0 & 5 & \\
\hline Ha cabbage & 0 & 30 & \\
\hline Cycles cabbage & 0 & 1 & \\
\hline Total Ha & 30 & 35 & 16.7 \\
\hline Employment (n) & 46 & 46 & 0.0 \\
\hline Profit (R) & 829,300 & $3,290,00$ & 296.7 \\
\hline \multicolumn{4}{|c|}{ Citrus Farm $2(\mathrm{M})$} \\
\hline Ha citrus old technology & 30 & 0 & -100.0 \\
\hline Ha citrus new technology & 0 & 30 & \\
\hline Ha cabbage & 0 & 30 & \\
\hline Cycles cabbage & 0 & 1 & \\
\hline Total Ha & 30 & 60 & 100.0 \\
\hline Employment (n) & 46 & 84 & 82.6 \\
\hline Profit (R) & 829,300 & 740,000 & -10.8 \\
\hline \multicolumn{4}{|c|}{ Citrus Farm $3(\mathrm{~L})$} \\
\hline Ha citrus old technology & 40 & 0 & -100.0 \\
\hline Ha citrus new technology & 0 & 30 & \\
\hline Ha cabbage & 0 & 0 & 0.0 \\
\hline Cycles cabbage & 0 & 0 & 0.0 \\
\hline Total Ha & 40 & 30 & -25.0 \\
\hline Employment (n) & 62 & 44 & -29.0 \\
\hline Profit (R) & $1,105,700$ & $2,710,00$ & 145.1 \\
\hline
\end{tabular}

Table 4 shows the dynamics in the village managers' decisions regarding water services and tariffs for their households. As a general trend, better water provision was introduced in all 
villages, and this was accompanied by an increase in water tariffs required from the households. In some cases the increase in domestic water tariffs was perceived too high by local residents (village L), affecting negatively their utility. On the other hand, this water tariff increase in village $\mathrm{L}$ triggered a huge improvement in the village manager's profit.

Table 4: Strategies and outcomes for the three villages during the RPG session: initial and final values

\begin{tabular}{lrrr}
\hline & Initial & \multicolumn{1}{c}{ Final } & Difference (\%) \\
\hline Village 1 (U) & & & \\
\hline Population (Inhab.) & 3,000 & 3,500 & 16.7 \\
\hline Share of river source & 0.8 & 0.0 & -100.0 \\
\hline Share of collective tap & 0.2 & 0.2 & 0.0 \\
\hline Share of indwelling tap & 0.0 & 0.8 & \\
\hline Water tariff (R/m ${ }^{3}$ ) & 1 & 2 & 100.0 \\
\hline Satisfaction index & 40.6 & 41.7 & 2.8 \\
\hline Manager's Profit (R) & 20,500 & 420,000 & $1,948.8$ \\
\hline Village 2 (M) & & & \\
\hline Population (Inhab.) & 5,000 & 5,500 & 10.0 \\
\hline Share of river source & 0.8 & 0 & -100.0 \\
\hline Share of collective tap & 0.2 & 0.2 & 0.0 \\
\hline Share of indwelling tap & 0 & 0.8 & \\
\hline Water tariff (R/m ${ }^{3}$ ) & 1 & 1.7 & 70.0 \\
\hline Satisfaction index & 40.6 & 42.89 & 5.7 \\
\hline Manager's Profit (R) & 34,180 & 300,000 & 777.7 \\
\hline Village 3 (L) & & & \\
\hline Population (Inhab.) & 15,000 & 16,000 & 6.7 \\
\hline Share of river source & 0.1 & 0 & -100.0 \\
\hline Share of collective tap & 0.4 & 0 & -100.0 \\
\hline Share of indwelling tap & 0.5 & 1 & 100.0 \\
\hline Water tariff (R/m ${ }^{3}$ ) & 1.5 & 2 & 33.3 \\
\hline Satisfaction index & 42.7 & 41.9 & -1.8 \\
\hline Manager's Profit (R) & 128,130 & $2,110,000$ & $1,546.8$ \\
\hline
\end{tabular}

It was clear that the WUA gave priority to the domestic uses of water, not hampering any initiative of water provision enhancement by the local managers. The respect of an ecological reserve set at 500,000 $\mathrm{m}^{3} /$ year in drought years and 750,000 in normal years was another WUA priority, due to recognition of legal requirements. Agricultural uses were more controlled and the release of new water licenses to farmers was less automatic, especially when the dam reserve became scarce (in the last three years of the RPG session). 
The water allocation policy by the WUA allowed positive results (profit) in terms of economic outputs for four farms out of five. Cabbage was more profitable than citrus due to a relatively steady trend in market price (excluding the final two years) and, more important, because no investment is required for new plantations. Farm 4 in the M sub-catchment registered the worst performance, paying the cost of heavy investment in new hectares planted at citrus combined with lower market prices in years 3 and 4. In addition, the session was too short to allow the farmer to recover the investment through the new citrus plants' production (in the RPG, citrus takes two years after plantation to become productive).

Job creation was generally positive for all farms. The water shortage provoked by the WUA's decision to stop releasing water in the last year had very negative impacts on job creation, particularly in the $\mathrm{M}$ and the $\mathrm{L}$ sub-catchments, where citrus is cultivated.

Table 5 shows also the dynamics of water consumption in the three sub-catchments. At year $1 \mathrm{~L}$ is the most water consuming (large village and large citrus farm) followed by M and $\mathrm{U}$. The latter consistently increased its water consumption during years 2 to 4 due mainly to the intensification of cabbage production. The slight increase in water consumption in the remaining sub-catchments is due to higher domestic demand. At year five, water consumption in $U$ decreased due to a change in strategy in one of the two irrigation schemes from three to two cycles of cabbage production per year. In year 6 the WUA decided to stop releasing water from the dam in order to allow it to refill.

The increasing water demand in the three sub-catchments is partially compensated by water releases from the dam decided by the WUA (Table 5). During the first four years of the game the WUA opted for the use of the Dam water to satisfy users' water demand and to provide a water flow in the river able to maintain ecosystem functioning (the ecological Reserve).

At the end of year 5, as the Dam level reached 1.3 million cubic meters, the WUA decided to stop suddenly and completely water releases. This decision contributed to an improvement in the dam water quantity, but had an immediate and dramatic consequence on the socio-economic and environmental indicators in the catchment. 
Table 5: Profit (R), job creation (n. of employees, rounded), water consumption $\left(\mathrm{m}^{3}\right)$ in the three sub-catchments; Dam level and Ecological reserve $\left(\mathrm{m}^{3}\right)$ for the whole basin

\begin{tabular}{|c|c|c|c|c|c|c|c|}
\hline Year & 1 & 2 & 3 & 4 & 5 & 6 & Annual/ \\
\hline & & & & & & & \\
\hline Profit U & 148,924 & 191,235 & 258,121 & 328,450 & 142,437 & $-127,311$ & 173,371 \\
\hline Profit M & $1,692,874$ & $1,089,725$ & 332,920 & $1,047,169$ & $1,196,990$ & $-949,883$ & 840,854 \\
\hline Profit L & $1,233,926$ & 688,012 & 337,207 & $1,330,596$ & $1,585,825$ & $-333,844$ & 875,872 \\
\hline Total Profit & $3,075,724$ & $1,968,972$ & 928,248 & $2,706,215$ & $2,925,252$ & $-1,411,038$ & $1,890,097$ \\
\hline Agric. profit U & 128,416 & 168,774 & 184,898 & 228,657 & 40,474 & $-234,938$ & 101,819 \\
\hline Agric. profit M & $1,658,694$ & $1,081,258$ & 256,006 & 991,829 & $1,132,383$ & $-1,038,061$ & 785,101 \\
\hline Agric. profit L & $1,105,796$ & 525,873 & 143,245 & 833,148 & $1,031,818$ & $-906,511$ & 522,400 \\
\hline Employment U & 102 & 140 & 179 & 191 & 108 & 102 & 137 \\
\hline Employment M & 92 & 119 & 133 & 142 & 156 & 130 & 129 \\
\hline Employment L & 62 & 76 & 77 & 84 & 85 & 44 & 71 \\
\hline Annual water cons. & 376,893 & 557,852 & 754,369 & 886,709 & 568,552 & 280,028 & 570,734 \\
\hline Annual water cons. & 464,526 & 612,535 & 657,732 & 800,720 & 843,208 & 564,019 & 657,123 \\
\hline Annual water cons. & 784,335 & 994,810 & 998,942 & $1,148,847$ & $1,193,328$ & 658,260 & 963,087 \\
\hline Dam level & $4,000,000$ & $3,674,800$ & $2,774,1$ & $1,814,240$ & $1,368,704$ & $2,361,648$ & $2,665,589$ \\
\hline Ecological reserve & $1,700,000$ & $1,500,000$ & 750,000 & 850,000 & 950,000 & 350,000 & $1,016,667$ \\
\hline
\end{tabular}

Table 5 allows a comparison of general socio-economic and environmental trends by subcatchment. Job creation is linked to the area cropped and to the intensity of production (cycles of cabbages on the same area); therefore, it closely follows the dynamics of water consumption. As a general trend, annual job creation is positive in all catchments (except for the last two years). Profit is more sensitive to water availability and during the first years of the game it is (negatively) influenced by high investments in the citrus farms. ${ }^{11}$ This is also why the profit of $\mathrm{M}$ and $\mathrm{L}$ decline dramatically during the game compared with that of $\mathrm{U}$, which increases. The net present value figures show clearly the dramatic impact of the WUA decision at year 5 on profit generation for the three sub-catchments. Again, M and L, where citrus farms are located, suffer due to the water shortage. Annual profit values are obtained by first calculating the net present value of the stream of profits for each sub-catchment and then spreading it over the game 
duration, using the capital recovery multiplier of 0.20336 . A $6 \%$ discount rate, reflecting the real interest rate in South Africa, and 6 years are used.

Finally, it is worthwhile noticing that the decision to stop completely water releases from the dam had a negative impact also on the ecological reserve, with flow of well below the limit of 500,000 cubic meters at year 6 . On average, the ecological reserve was kept at about 1 million $\mathrm{m}^{3} /$ year, corresponding to $40 \%$ less than its level at the beginning of the negotiation game session, but 33\% more than the limit set for wet years and 100\% more than the limit set for dry years.

\section{Formulating water allocation decisions as a cooperative game}

The Cooperative Game Theory (CGT) model will introduce several assumptions. We assume that the players are rational, price takers ${ }^{12}$ and profit maximizers. They will engage in cooperative arrangements only if it can improve their economic situation compared with the status quo.

The watershed includes three players (each with several water activities), Upper, Middle, and Lower sub-watershed-U, M, L, as is described in the right rectangle of Figure 1 (we will use $i=1$ for $U, i=2$ for $M$, and $i=3$ for $L$ ). There is a water storage (dam) in the $U$ sub-watershed, and an outlet of the river beyond the $\mathrm{L}$ sub-watershed (we will refer from hereafter only to watershed). There is a deterministic rainfall quantity that falls on the area of each watershed and ends up in the river. There are no losses of water and all the rainfall can be used as a source for the water-activities (this assumption can also be modified by having a fraction of the rainfall available for use, assuming losses and evaporation). So, each player refers to the amount of rainfall on its area as water in the river available for use. There are also ground water sources not yet fully developed, so they are not included. Players can also use water from the reservoir that is released (flushed) by the WUA upon a request from the player (if supplies last). The WUA can refuse to supply water from the reservoir if the amount in the reservoir is below a given level.

The WUA in our game is the authority that oversees and regulates the players' behavior. From the point of view of CGT, the WUA could decide on an allocation of water that respects principles on which it has been agreed upon (e.g., Social Equity, Environmental Sustainability and Economic Efficiency). It is assumed that the players obey the WUA rules of behavior. The 
objective of each player is to maximize annual profits subject to water availability, prices and costs, and the WUA rules of behavior.

Rules of behavior that are respected by the players are that no player extracts water that runs in the river that doesn't belong to that player. Such water include the ecological Reserve that flows through segments running through $\mathrm{U}, \mathrm{M}$, and $\mathrm{L}$, or water that was released from the dam at the request of a given player and has to run in the river through the 'territory' of other players. While such behavioral requirements may look naïve in light of cheating attempts on the part of the users, one can include monitoring and enforcement costs associated with operating such system in real world situation.

The Cooperative game played is an annual one. Therefore, constraints for each player include (1) fixed citrus land, (2) limited land for cabbage, (3) fixed number of inhabitants consuming water, (4) given amount of rainfall that can be utilized via the flow of the river. The CGT uses the values applied in the RPG. Constraints or rules for the WUA (or at the Kat watershed) include: (1) a given amount of water in the storage at the beginning of the year, (2) a given amount of water required in the storage at the end of the year, (3) a given amount to be released from the Kat to the Fish river, (4) a given amount to be left in the river for local benefits, (5) a minimum annual amount of water per inhabitant to fulfill human needs. (6) a given amount of available laborers to work in citrus or cabbage operations. It is assumed that these laborers can move freely between the three watersheds. Additional assumptions represent the linkage between the water use and water flow in the river. These linkages are expressed in the equations of the CGT game model in the Annex.

We investigate the likelihood of cooperation among the three players, U, M, L. CGT introduces the concept of the characteristic function for each set of coalitional arrangements among the players in the watershed. A characteristic function is the best outcome of a coalition. Further assumptions are needed. In our CGT analysis we consider a one-year game period. The essential aspect of this choice is that we shall not consider investment decisions ${ }^{13}$. This is a clear limitation, but we observe that in the RPG players are not in a position to make optimal investment decisions (especially due to the short time span allowed). Hence, the one year time span that we use in the CGT approach should offer an appropriate benchmark as far as evaluation of the RPG and CGT is considered. 
Let us start with the status quo individual coalitions. The status quo is represented by each player (watershed) working on their own to maximize their utility/profits from the available water they have, subject to individual constraints of each player and rule of behavior constraints imposed by the WUA. There is no special treatment of the water activities and the land constraints. However, in the maximization problem for each player in the case of the status quo, we need to add several assumptions to deal with the watershed constraints: labor, minimum ecological flow in the Kat River, and a given amount be released for the Fish River. ${ }^{14}$ We will assume a total amount of available labor in the watershed and a total amount of environmental flow to be released to the Fish River. The total available labor to each player will be based on the relative total available land of that player (indicating the potential employment ability of that player). The allocation of the environmental flow amount will be made based on the basis of the total amount of water used by that player. The minimum flow in the Kat river will be simply deducted from the available amount of water for each player.

In the next step we move to the calculation of the characteristic functions of the partial coalitions. We assume that all permutations are possible, even that between player $1(\mathrm{U})$ and player $3(\mathrm{~L})$. However, for these players we shall simply assume that what they can achieve in cooperating with each other is just the sum of what they can get separately. The difference between the calculation of the value of the other partial coalitions and the individual coalitions will be that the decision on water allocation and the total amounts of the minimum flow and the environmental flow can be made jointly rather than individually. Additionally, the allocation of the rule values for labor, minimum flow and environmental flow will follow the pattern suggested in the case of the individual coalition calculations.

And finally we move to calculate the characteristic function of the grand coalition. In this case the labor constraint is at the watershed level, the minimum flow constraint is also at the watershed level, and the environmental flow constraint can be met at the outlet of the Kat when it leaves the area of Player $3(\mathrm{~L})$.

Let us now introduce the variables (remember that $i=1,2,3$ is equivalent to $i=U, M, L$ )

$F_{i \alpha}$ is the (natural) available flow (with probability greater or equal than $\alpha$. In our model, $\alpha=1$ ) in watershed $i$. 
$S_{i}$ is the stream entering watershed $i\left(S_{1}=0\right)$.

$E_{i}$ is ecological reserve constraint for part $i$ (flow leaving part $i$ ). Since the ecological reserve level that is of interest is the quantity that leaves the watershed, each watershed $i$ is expected to release to the next one, and $\mathrm{L}$ is expected to release to the environment that same quantity, it will be denoted by $\mathrm{E}$. This is another simplifying assumption, as the level of $\mathrm{E}$ in each watershed $i$ could quite be a decision variable.

$C_{i}$ : water for domestic use in part $i$.

$W(D)$ is the additional water available from the dam.

A player, or a coalition, will use its available water, to maximize its revenue. Actually, we assume that each player solves an optimization problem to maximize the use of the available water via allocation among all possible water uses. The plan that maximizes the returns is called the characteristic function of the coalition/player. A very general exposition of the optimization problem (generalized to each coalition) is as follows: ${ }^{15}$

Max
water from dam, water fee,
water from river $\left\{\begin{array}{l}(\text { land under citrus }) ;(\text { land, water intensity, } \\ \text { cycles of cabbage); (water consumption in villages by source); } \\ \text { (environmental release) }\end{array}\right\}$

Subject to :

(1) environmental reserve outflow

(2) rain availability

(3) water in river

(4) land

(5) labor force

(6) other institutional and technical constraints

Such an optimization problem is solved to yield solutions to the following coalitions (individuals, partials, and grand coalition) $\{U\},\{M\},\{L\},\{U, M\},\{M, L\}$, and $\{U, M, L\}$. The solution for each coalition, the characteristic functions are denoted by: $v(\{U\}), v(\{M\}), v(\{L\})$, $\mathrm{v}(\{\mathrm{U}, \mathrm{M}\}), \mathrm{v}(\{\mathrm{M}, \mathrm{L}\})$, and $\mathrm{v}(\{\mathrm{U}, \mathrm{M}, \mathrm{L}\})$. Note that according to our simplifying assumption $\mathrm{v}(\{\mathrm{U}, \mathrm{L}\})$ will be replaced by $\mathrm{v}(\{\mathrm{U}\})+\mathrm{v}(\{\mathrm{L}\})$. 
Using various game theory solution concepts, allocations of payoffs are made among the three players. We use for demonstration the Shapley Value solution concept (Shapley, 1971):

$\phi_{i}=\frac{1}{n} \sum_{s=1}^{n} \frac{1}{c(s)} \sum_{\substack{i \in S \\|S|=s}}[v(S)-v(S \backslash\{i\})], \quad i=\mathrm{U}, \mathrm{M}, \mathrm{L}$

where $c(s)$ is the number of coalitions of size $s$ containing player $i$ :

$c(s)=\left(\begin{array}{c}n-1 \\ s-1\end{array}\right) \equiv \frac{(n-1) !}{(n-s) !(s-1) !}$.

Another CGT solution concept, the Nucleolus (Schmeidler, 1969), is used also (we don’t provide the definition of the Nucleolus; the interested reader can find it also in standard references, as Owen, 1995). The Nucleolus always lies in the core, provided that it is non empty. In our results, the values of the Nucleolus differ very little from those of the Shapley value.

\subsection{CGT solution results}

Based on our model calculations (Annex), the following are the characteristic values of the Kat CGT (in Rands):

$\begin{array}{lr}\mathrm{v}(\{\mathrm{U}\})= & 336,060 \\ \mathrm{v}(\{\mathrm{M}\})= & 1,758,946 \\ \mathrm{v}(\{\mathrm{L}\})= & 1,185,693 \\ \mathrm{v}(\{\mathrm{U}, \mathrm{M}\})= & 2,341,140 \\ \mathrm{v}(\{\mathrm{U}, \mathrm{L}\})= & 1,521,753 \\ \mathrm{v}(\{\mathrm{M}, \mathrm{L}\})= & 2,944,639 \\ \mathrm{v}(\{\mathrm{U}, \mathrm{M}, \mathrm{L}\})=3,552,913\end{array}$

The resulting Shapley allocation is:

$\phi_{U}=\quad 467,820.33$

$\phi_{M}=\quad 1,890,706.33$

$\phi_{L}=\quad 1,194,386.33$ 
with

$\phi_{U}+\phi_{M}+\phi_{L}=v(\{U, M, L\})$, since the Shapley value provides an efficient allocation,

$\phi_{i} \geq v(\{i\}), \quad i=U, M, L$, which suggest individual rationality, and

$\phi_{U}+\phi_{M} \geq v(\{U, M\}), \phi_{U}+\phi_{L} \geq v(\{U, L\})$, and $\phi_{M}+\phi_{L} \geq v(\{M, L\})$ which suggests group rationality (otherwise stated, the Shapley value lies in the core).

The payoff is distributed among the three players such that $\mathrm{U}, \mathrm{M}$, and L get 13, 53 and 34 percent of the total cooperative profits, respectively. $U$ is clearly the main beneficiary from the CGT allocation, increasing its share in the cooperative payoff by 39 percent compared with the non cooperation payoff, while both $\mathrm{M}$ and $\mathrm{L}$ gained 7 and 1 percent, respectively. The CGT assumes utility transfer in the form of payments (or compensations).

For the Nucleolus, the allocation is: 465,647 for $U, 1,888,533$ for $M, 1,198,733$ for $L$. Since the core is non empty (the Shapley value, as seen, lies in it), the Nucleolus is also in the core. Since the allocation provided by the Nucleolus are so close to those provided by the Shapley value (the differences are by far smaller than variations due to the approximations used or to the assumptions done), the same comments in the next section will apply for both.

\section{Evaluation of the negotiation and cooperative game theory allocations}

In this section we will attempt at evaluating the results from the RPG and the CGT allocations. We will review the basic features of the RPG and CGT approaches that lead to the solutions obtained. We will then suggest some extensions that may be likely to bring the results of the two closer. We first display the annualized allocations of profits by the RPG, The Shapley Value and the Nucleolus (Table 6).

Table 6: Allocation of annual (and annualized) profits according to the RPG, Shapley Value and the Nucleolus in the Kat game.

\begin{tabular}{|lccl|}
\hline Player & RPG & Shapley Value & Nucleolus \\
\hline $\mathrm{U}$ & 173,371 & 467,820 & 465,647 \\
\hline $\mathrm{M}$ & 840,854 & $1,890,706$ & $1,888,533$ \\
\hline $\mathrm{L}$ & 875,872 & $1,194,386$ & $1,198,733$ \\
\hline Total & $1,890,097$ & $\cong 3,552,913$ & $3,552,913$ \\
\hline
\end{tabular}


Any comparative evaluation of the NA/RPG and CGT outcomes has to be subject to several caveats. First, the RPG is based on an experimental negotiation framework and the CGT is based on an axiomatic model. Second, the RPG has a dynamic nature that we cannot capture with the present version of the CGT model. And third, the main differences (in the RPG and the CGT) in the calculations of the profits of the players lead to possible discrepancies between the total and individual profits. While the calculation of profits to the $\mathrm{U}, \mathrm{M}$, and $\mathrm{L}$ players in the case of the CGT are a result of an optimization process that takes into account a very strict set of variables, the RPG process incorporates 'real' players that take into consideration many more factors than the algorithm used in the CGT. Just these two caveats may explain possible differences in total catchment outcomes. As for the behavior of individual players, observations from the RPG session suggest that both irrigators and village managers aim at improving their respective indicators of performance (profit for irrigators; profit + residents' satisfaction for village managers) without necessarily maximizing them. This might be due to a lack of information on the possible alternative strategies they could adopt during the RPG session and refers to a behavior called "satisficing", where satisficing is an alternative to optimization for cases where there are multiple and competitive objectives in which one gives up the idea of obtaining a "best" solution (Simon, 1992). Players therefore adopt year after year strategies of incremental improvement of their indicators. These strategies take into account external factors and must be discussed within (and cleared by) the WUA before they can be put in practice. In addition, willingness to reach an improved state does not correspond necessarily to an improved state of the players all through the RPG session: lack of play skills or external factors' dynamics worse than forecasted can be the causes of performances less positive than expected.

As can be seen from Table 6, the catchment profit (outcome) based on the RPG outcomes is 1.891 million Rand on an annualized basis for each of the 6 years. The annual profit based on the CGT characteristic function calculations is 3.553 million. The difference is due to economic decisions that are based on different algorithms and assumptions. While the total payoff at the catchment level may be different in the RPG and CGT procedures, due to use of different assumptions, we would have a more useful insight from the distribution of the payoff among the players. In our case, the three sub-catchments $\mathrm{U}, \mathrm{M}$, and L shares in the catchment total profit was 9, 45 and 46 percent respectively in the RPG based on the annualized allocation, and 13, 53 
and 34 percent respectively in the CGT solution. Note the equal share of profit for $\mathrm{M}$ and $\mathrm{L}$ in the RPG solution, compared with a lower share to L (compared with M) in the CGT solution.

\section{Conclusions and extensions}

This paper developed a framework that helps to evaluate CGT and RPG outcomes to a problem of water and outcome allocations among competing uses. Such a framework is useful for several reasons. First it allows the analysts to assess the nature of the assumptions made during the calculations or negotiation session. Second it creates feedback loops between the CGT and the RPG to consider further development of the tools. And third, it may suggest complementary roles for each approach under different conditions that the parties in the allocation problem face.

Acknowledging the overly simplified optimizations procedure in the case of the CGT, it is suggested that the baseline scenario in CGT will be modified in order to address new constraints and scenarios that have been considered in the RPG session. This will include the dynamic nature of the allocation problem, and various structures to consider the environmental flow needs. Future sessions of the RPG will take CGT results into consideration, such as allowing for negotiation among sub-catchments, and integrating the WUA to be part of the sub-catchments to eliminate unilateral decisions such as the one to stop releasing water from the dam.

\section{References}

Aadland, D. and Kolpin, V. (2004) 'Erratum to Environmental Determinants of Cost Sharing', Journal of Economic Behavior and Organization, 55: 105-121.

Barreteau, O., Bousquet, F., and Attonaty, J.M. (2001) 'Role-playing games for opening the black box of multi-agent systems: method and lessons of its application to Senegal River Valley irrigated systems', Journal of Artificial Societies and Social Simulation, 4(2), $<$ http://www.soc.surrey.ac.uk/JASSS/4/2/5.html>.

Barreteau, Olivier and others (2003) ‘Our Companion Modelling Approach’ Journal of Artificial Societies and Social Simulation, 6 (1), <http://jasss.soc.surrey.ac.uk/6/2/1.html>.

Becu, N., Perez, P., Walker, A., Barreteau, O. and Le Page, C. (2003) 'Agent based simulation of a small catchment water management in northern Thailand: description of the CATCHSCAPE model', Ecological Modelling, 170: 319-331.

Carraro, C., Marchiori C. and Sgobbi A. (2005a) Application of Negotiation Theory to Water Issues, Policy Research Working Paper 3641, World Bank, Washington DC.

(2005b) Advances in Negotiation Theory: Bargaining, Coalitions and Fairness, Policy Research Working Paper 3642, World Bank, Washington DC. 
Dray, A., Perez, P., Jones, N., Le Page, C., D’Aquino, P. and Auatabu, T. (2006) The AtollGame experience: from knowledge engineering to a computer-assisted role playing game, Journal of Artificial Societies and Social Simulation, 9 (1), $<$ http://jasss.soc.surrey.ac.uk/9/1/6.html>.

DWAF (2001) Fish to Tsitsikamma Water Management Area, Water Resources Situation Assessment, WMA 15 Report No. P WMA 150000/00/0203.

Farolfi, S. and Abrams, M. (2005) 'Water uses and their socio-economic impact in the Kat River catchment, A report based on primary data', Unpublished Water Research Commission Report, Project no K5/1496, Institute for Water Research, Rhodes University, Grahamstown.

Farolfi, S. and Bonté, B. (2005) 'KatAWARE: A negotiation-support tool for participatory water resource management in the Kat River Valley (Prototype model)', Unpublished Water Research Commission Report, Project no K5/1496, Institute for Water Research, Rhodes University, Grahamstown.

Farolfi, S. and Rowntree, K. 'Accompanying Local Stakeholders in Negotiation Processes Related to Water Allocation Through Simulation Models and Role-Playing Games: an Experience from South Africa', paper presented at the Conference 'End-user Ownership and Involvement in Integrated Water Resource Management', Cairo, Egypt, November 1317, 2005. Available: www.empowers.info/page/704

Farrington, J. and Boyd, C. (1997) 'Scaling up the Participatory Management of Common Pool Resources’, Development Policy Review, 15(4): 371-391.

Lankford, B. and Watson, D. (2006) 'Exploring metaphor in natural resource gaming: insights from the River Basin Game', in Barreteau, O., Etienne, M., Le Page, C., and Perez, P. (eds.). Symposium issue of Simulation \& Gaming, SAGE, USA.

McMaster, A. (2002) 'GIS in participatory catchment management : a case study in the Kat River Valley, Eastern Cape, South Africa’, Unpublished MSc Thesis, Rhodes University

Munro, G. (1979) 'The Optimal Management of Transboundary Renewable Resources', Canadian Journal of Economics, 12(8): 355-376.

Ostrom, E. (1992) Crafting Institutions for Self-Governing Irrigation Systems, Institute for Contemporary Studies, San Francisco, CA.

Ostrom, E., Gardnner, R. and Walker, J. (1994) Rules, Games, \& Common-Pool Resources, The University of Michigan Press.

Owen, G, (1995) Game Theory, Academic Press, San Diego.

Parrachino, I., Dinar, A. and Patrone, F. (2006) Cooperative Game Theory and its Application to Natural, Environmental and Water Resource Issues. 3. Application to Natural andEnvironmental Resources. Policy Research Working Paper 4074, World Bank, Washington DC.

Goodhue, R.E. and McCarthy, N. (2007) Traditional Grazing Rights in Sub-Saharan Africa and the Role of Policy, in: Dinar, A., J. Albiac and J. Sanchez-Soriano (Eds.) Playing Games With Nature: Game Theory, Natural Resources and the Environment. London: Routledge. 
Schmeidler, D. (1969) 'The Nucleolus of a Characteristic Function Game', SIAM Journal of Applied Mathematics, 17:1163-1170.

Shapley, L.S. (1953) 'A Value of N-person Games', Annals of Mathematical Studies, 2(28): 307318.

Simon, H.H. (1992) 'Methodological foundations of economics', in Auspitz, J.L. et al. (eds.) Praxiologies and the philosophy of economics, Transaction Publishers, New Brunswick, N.J.

Steins, N.A. and Edwards, V.M. (1999) 'Platforms for Collective Action in Multiple-Use Common Pool Resource Management', Agriculture and Human Values, 16(3): 241-255.

White, T.A. and Ford Runge, C. (1994) 'Common Property and Collective Action: Lessons from Cooperative Watershed Management in Haiti', Economic Development and Cultural Change, 43: 1-20. 


\section{Annex: The formulation of the characteristic function}

The physical model

Denote by $D^{0}$ the water stock behind the dam at the beginning of the planning period. $R_{i}$ ( $i=1,2,3$ ) is the amount of rainfall on the area of player $i$. We interpret that variable also to be the amount of water available for use by player $i$, and also the amount of water in the river that player $i$ can use. $D_{i}$ is the request for flashes of water from the dam operator by player $i . R_{1}^{D}$ is the amount of water stored behind the dam during the planning period. As noticed, only rainfall in the part of the area of player 1 can be dammed. $D$ will be the amount of water behind the dam that can be used during the planning period.

Several relationship hold so far:

[1] $\quad R_{1}^{D} \leq R_{1}$

$$
D=D^{0}+R_{1}^{D} \geq \sum_{i} D_{i}
$$

We further denote by $W_{i}$ the total demand for water, during the planning period, by player $i$ and by $E$ the demand (allocation) for environmental needs where the watershed ends and the Kat River becomes a tributary of the Fish River. This occurs after player UL's area.

Here we add several more relationships:

$$
W_{i} \leq S_{i}
$$

Where, $S_{i}$ is the supply of water available to player $i$ as follows:

$$
S_{1}=D_{1}+R_{1}-R_{1}^{D}
$$

[5] $\quad S_{2}=D_{2}+R_{2}+\left(S_{1}-W_{1}\right)$

[6] $\quad S_{3}=D_{3}+R_{3}+\left(S_{2}-W_{2}\right)$, and finally

We need now to include more specific relationship representing the total water demand by each player. Given the water use patterns by each player, there are agricultural uses (citrus and cabbage), and domestic uses (in the villages and urban centers). This amount is imposed on the watershed and is subject to a policy decision. 
For our purposes, let $V_{i}^{v}, V_{i}^{u}, C_{i}^{C}$, and $C_{i}^{B}$ be the amounts of water used by the village, the citrus, and the cabbage, respectively, for player $i$. The total demand for water by player $i$ is:

[7] $W_{i}=V_{i}^{v}+V_{i}^{u}+C_{i}^{C}+C_{i}^{B}$.

\section{Additional constraints}

The WUA imposes minimum flow $\left(M F_{i}\right)$ to keep the river flowing in each subwatershed. This minimum flow amount is deducted from each player's amount of available water $S_{i}$.

[8] $S_{i}^{M F}=S_{i}-M F_{i}$

In addition, the WUA imposes the environmental flow constraint. We will handle that constraint in the following way:

A total of EF has to leave the Kat to the Fish river. This amount has to fulfill the following relationship:

[9] $E F \leq \sum_{i} E F_{i}$

The optimization process in each sub watershed

The villages

Villages. Assume that each village has a given population $N_{i}^{v}$, that the annual water consumption per person is $v_{i}^{v}$, the cost of providing each unit of water is $P^{v_{i}^{v}}$, and that the utility per inhabitant in the village from being provided a unit of water is $u^{v_{i}^{v}}$. We assume that the utility is linear in money. For simplicity assume that the ratio is $1: 1$. The total 'benefits' from providing water to the village is therefore:

$U_{i}^{v}=V_{i}^{v} \cdot\left(u^{v_{i}^{v}}-P^{v_{i}^{v}}\right)$, where

$V_{i}^{v}=N_{i}^{v} \cdot v_{i}^{v}$

We introduce a constraint on the minimal amount per year that a village inhabitant should be receiving per year.

[10] $v_{i}^{v} \geq \underline{v}$. 


\section{The citrus industry}

Assume that citrus is grown with three factors of production, namely land, water and labor. Since we deal with a perennial crop and we assume no investment in new plantation, we will have the area of citrus in each sub-watershed fixed at $L_{i}^{C}$. Since in our model the area is fixed, the decision growers make is how much water per hectare to apply, including also no irrigation that end up with a minimum yield (Farolfi and Bonte, 2006).

The payoff for citrus production in watershed $\mathrm{i}$ is:

$F_{i}^{C}=L_{i}^{C} \cdot\left[Y_{i}^{C}\left(C_{i}^{C}\right) \cdot P^{C}-C_{i}^{C} \cdot P_{i}^{C_{i}^{C}}-B_{i}^{C} \cdot P^{B}\right]$, where

$Y_{i}^{C}\left(C_{i}^{C}\right)$ is the citrus production function. It has a positive intercept at $C_{i}^{C}=0 ; P^{C}$ is the price per unit of citrus produced, which is a function of the amount of water applied per hectare, $C_{i}^{C}$; $P_{i}^{C_{i}^{C}}$ is the cost of water charged to the citrus operation in subwatershed i. Note that we allow different water charges per crop and subwatershed; $B_{i}^{C}$ is the labor per hectare of citrus; and $P^{B}$ is the cost per unit of labor, assuming the same for the entire Kat.

The cabbage industry

The cabbage industry production is very similar to that of the citrus except that, under our set of assumptions, the land for growing cabbage is not fixed (however, for realism we impose a constraint of 60 ha on the extension of land that can be used for cabbage; this constraint turns out to be binding only for player $U$ and for the subcoalition $\{U, M\})$. In the case of cabbage, the growers do not vary the amount of water per hectare, but decide only the area to be cultivated with cabbage with a given amount of water per ha. The payoff per hectare of cabbage is: $F_{i}^{B}=L_{i}^{B} \cdot\left[C_{i}^{B} \cdot P^{B}-C_{i}^{B} \cdot P_{i}^{C_{i}^{B}}-B_{i}^{B} \cdot P^{B}\right]$, where

$P^{B}$ is the cost per unit of cabbage produced (cost of labor has the same symbol; $C_{i}^{B}$ is the amount of water applied per hectare of cabbage; $P_{i}^{C_{i}^{B}}$ is the cost of water charged to the cabbage operation in subwatershed $\mathrm{i} ; B_{i}^{B}$ is the labor per hectare of cabbage. Cabbage growers decide on the area they plant with cabbage $L_{i}^{B}$. 
The objective function of watershed $i$

Watershed i maximizes payoff from the three activities, subject to physical and institutional constraints:

[12] $Y_{i}=\underset{V_{i}^{v}+C_{i}^{C}+C_{i}^{B}}{\operatorname{Max}}\left\{U_{i}^{u}+U_{i}^{v}+F_{i}^{C}+F_{i}^{B}\right\}, i=1,2,3$

s.t. the relevant constraints in [1]-[10]

The characteristic functions

The characteristic function of the individual coalitions are actually a solution to an LP problems that are based on the coalition at stake. In the case of the individual coalitions we solve [12] subject to relevant constraints in [1]-[10], and imposed rules of allocation of water from the Dam, Allocation of the minimum flow and allocation of the environmental flow among players 1, 2, 3.

Then we have the possibility of subcoalitions. Clearly a coalition of $\{1,2\}$ and a coalition of $\{2,3\}$ can be envisioned. As said, a coalition of $\{1,3\}$ is less obvious. We can include such coalition on the premise that the WUA enforces rules and water transfers that are respected by its members. 


\section{Notes}

\footnotetext{
${ }^{1}$ Modified from Farolfi and Rowntree (2005).

2 "Emerging" citrus farmers are black farmers that after 1994 had the right to exploit (and not own) citrus farms located during Apartheid period in the Ciskei Bantustan and previously owned and managed by the public Bantustan's administration.
}

${ }^{3}$ The IB was substituted lately by a more participatory Water User Association (WUA) including representatives of all main groups of stakeholders in the Kat. This organization is now in charge of defining the water "business plan" indicating water allocation strategies and resource management for the catchment. While the difference between the IB and WUA may not be essential for the CGT, it is very important for the negotiation process, as will be discussed later.

${ }^{4}$ Developing groundwater resources in the watershed would help irrigators overcome droughts. However, in this paper GW development is not considered due to need for external financial support.

${ }^{5}$ Defined in the National Water Act as "the quantity and quality of water required to protect the aquatic ecosystems of the water resource in order to secure ecologically sustainable development and use of the resource.”

${ }^{6}$ These portions of the catchment correspond to the three voting areas identified to nominate the Kat River Valley Water Users Association representatives (Figure 1).

${ }^{7}$ ha=hectare. 1 ha= 2.5 acre.

${ }^{8}$ The conversion factors for the different variables range between 2.1 (Inhabitants in catchment) and 13 (Area citrus). The arbitrary choice of the conversion factors was due to the trade-off between having an RPG that represents the reality and an RPG that is "playable”. It may be noticed that players validated the RPG representation of the Kat during the first session. The only criticism was for the disproportionately high importance of domestic water consumption in the RPG compared to the real one. This issue was addressed in a second version of the RPG by changing the conversion factor of "Inhabitants in catchment" from 2.1 to 4.9.

${ }^{9}$ For production and profit functions used in the KatAware model that supports the RPG, see the characteristic functions used also for the CGT model.

${ }^{10}$ The Capital Recovery Multiplier equation used is $\left[r \cdot(1+r)^{t}\right] /\left[(1+r)^{t}-1\right]$, where $r$ is discount rate (0.06), and $t$ is number of years of the game $(t=6)$.

${ }^{11}$ In this game, profit=total income-total costs. If a farmer invests in citrus plantations, therefore, his annual income during the first years of new orchards is constant (no production) whilst the costs increase. It was noticed by citrus farmers during the game debriefing that this is not really how they see things because an investment is calculated as a positive asset in their budget, whereas here is a negative (cost) one. They suggested calling "cash-flow" what we call "profit" in the game outcomes.

${ }^{12}$ Face given prices rather than affecting the prices in the market.

${ }^{13}$ We should stress that the formulation of our CGT problem allows considering longer time horizons by creating for each player and coalitions optimization problems that span over $\mathrm{T}$ years but what the player considers is the expected annualized value.

${ }^{14}$ We assume that the ecological reserve serves both for environmental health in the Kat River and for releases into the Fish River's estuary.

${ }^{15}$ A multi-year problem will be developed in our future work. 